\title{
The Effect of Humanistic Care on Gynecological Tumor Patients
}

\author{
Manli Huang, Xinke Huang*, Qiufang Zhang, Xuefeng Jiang \\ Gynecology Department, The First Affiliated Hospital of Jinan University, Guangzhou, China \\ Email address: \\ 13826197465@163.com (Manli Huang),929901838@qq.com (Xinke Huang),957773931@qq.com (Qiufang Zhang), \\ xuefengjiang@126.com (Xuefeng Jiang) \\ ${ }^{*}$ Corresponding author
}

\section{To cite this article:}

Manli Huang, Xinke Huang, Qiufang Zhang, Xuefeng Jiang. The Effect of Humanistic Care on Gynecological Tumor Patients. Journal of Cancer Treatment and Research. Vol. 8, No. 1, 2020, pp. 18-20. doi: 10.11648/j.jctr.20200801.13

Received: January 18, 2020; Accepted: February 10, 2020; Published: February 18, 2020

\begin{abstract}
Objective: To evaluate effect of humanistic care on gynecological tumor patients. Methods: 112 patients diagnosed as gynecological tumor from January 2017 to June 2018 in hospital. The participants were randomly assigned to control group and intervention group. We use new nursing of humanistic care for the patients of intervention group. In control, the patients had traditional nursing services. The data was collected by medical history, Visual Analogue Scale (VAS), Pittsburgh sleep quality index (PSQI) and Newcastle Satisfaction with Nursing Scales (NSNS). Result: Most of participants had cervical cancer [34 $(30.4 \%) \& 41(36.6 \%)$ ]. Besides, nursing measure of intervention group had better influence than traditional nursing measure of control group (Pain level, $1.21 \pm 0.33$ vs 3.04 \pm 0.44 ; sleep quality, $13.74 \pm 2.34$ vs 10.49 \pm 2.51 ). In assessment of patients satisfaction, the assessments of very well were made by 88 (71.4\%) people in intervention group. Conclusion: humanistic care can be effectively improved the outcome of treatment on gynecological tumor patients. The nursing measure of humanistic care made not only pain level of patient in treatment process was reduce but also sleep quality of patient was improved. However, the improvement effect was not strong for the outcome of nursing so that the new nursing measure had low effective rate in the treatment process.
\end{abstract}

Keywords: Humanistic Care, Gynecological Tumor, Nursing

\section{Introduction}

Nursing was identify as a profession that is closely related to human health and human life, with emphasis on caring and caring for the patients [1]. As increased patients need spiritual and psychological comfort, treatment participation, and comprehensive services, the services which included the value of the individual, care, warmth and compassion were required to add to the the daily nursing work $[2,3]$. This presents that humanistic caring is a important part of nursing in treatment process $[4,5]$. The humanistic care make the better daily nursing, it not only provide effective clinical practice and offer high quality of care in hospitals but also contributes to improvement on metrics such as higher patients' satisfaction, less work pressure and better doctor-patient relationship [6].

Although Chinese nursing service was improved continuously, the patients were not satisfied with the Chinese care provided in most cases. Because some nurses still ignore the psychological and social care of patients in clinical work, which may lead to a lower overall humanistic care ability of nurses in China [7, 8]. Watson, Fernandezabascal and Martindiaz think that nursing humanistic care was the nurses' externalization of humanistic literacy into the clinical work and abilities to serve the patients consciously and creatively [9, 10]. Following to some reports, high emotional intelligence was good for nurses communicate well with patients in treatment process [11 - 13]. Our study aim was that assess the effect of humanistic care on gynecological tumor patients.

\section{Methods}

\subsection{Participants Enrollment and Survey Methods}

The patients $(\mathrm{n}=224)$ were diagnosed as gynecological tumor which included ovarian cancer, cervical cancer, fallopian tube malignant tumor, endometrial cancer and other, 
they were investigated to join our study. The data of patient was collected from January 2017 to June 2018. In study beginning step, the participants were randomly assigned to a control group $(n=112)$ and a intervention group $(n=112)$. For participants of control group, we use the traditional nursing care for them in treatment process [14]. The participants of another group, they were receipted extra humanistic care in treatment process. The humanistic care included that new communication skills, psychological assessment of patients and new nursing measure. Our researchers collected the result which included the participants character, the satisfaction of patients, pain status and sleep quality by medical history, Visual Analogue Scale (VAS), Pittsburgh sleep quality index (PSQI) and Newcastle Satisfaction with Nursing Scales (NSNS) [15-17].

Their inclusion criteria were: (1) the patients were diagnosed as gynecological tumor; (2) Patients volunteered to participate in postoperative follow-up; (3) Cognitively and mentally were normal. Their withdraw criteria were: (1) Survival is expected to be less than 90 days; (2) Patients with severe vital organ dysfunction or related mental illness.

\subsection{Statistical Analysis}

Survey responses were analyzed using descriptive statistics. Sample proportions, means, and standard deviation (SD) are reported. All analyses were performed in SPSS 25.

\section{Result}

The data associated with participants characteristics was collected by search patient record as the participants join into our study (Table 1). Most of participants had cervical cancer [34 (30.4\%) \& 41 (36.6\%)]. Additionally, their marital status was married, they had family to support them.

Table 1. Participants Characteristics.

\begin{tabular}{|c|c|c|c|c|}
\hline Projects & Intervention Group, n (\%) & Control Group, n (\%) & $X^{2}$ & P value \\
\hline \multicolumn{5}{|l|}{ Cancer types } \\
\hline Ovarian cancer & $23(20.5 \%)$ & $16(14.3 \%)$ & \multirow{5}{*}{2.462} & \multirow{5}{*}{$<0.005$} \\
\hline Cervical cancer & $34(30.4 \%)$ & $41(36.6 \%)$ & & \\
\hline Malignant tumor of fallopian tube & $24(21.4 \%)$ & $13(11.6 \%)$ & & \\
\hline Endometrial cancer & $11(9.8 \%)$ & $21(18.8 \%)$ & & \\
\hline choriocarcinoma & $20(17.9 \%)$ & $19(17.0 \%)$ & & \\
\hline \multicolumn{5}{|l|}{ Marital status } \\
\hline Married & $93(83.0 \%)$ & $102(91.1 \%)$ & \multirow{2}{*}{1.259} & \multirow{2}{*}{0.355} \\
\hline Unmarried & $19(17.0 \%)$ & $17(15.2 \%)$ & & \\
\hline Weight $(\mathrm{Kg})$ & $60.77 \pm 8.03$ & $59.40 \pm 8.68$ & 3.2 & 0.221 \\
\hline Age (Years) & $40.06 \pm 3.53$ & $39.35 \pm 2.97$ & 0.281 & 0.281 \\
\hline Course of the disease (Months) & $5.56 \pm 1.28$ & $5.27 \pm 1.21$ & 0.704 & 0.704 \\
\hline
\end{tabular}

We collected the result of Pain level and sleep quality by VAS and PSQI, they completed the questionnaires after treatment (Table 2). The pain status and sleep quality were improved on participants of both of groups. But Nursing measure of intervention group had better influence than traditional nursing measure of control group (Pain level, $1.21 \pm 0.33$ vs $3.04 \pm 0.44$; sleep quality, $13.74 \pm 2.34$ vs $10.49 \pm 2.51)$.

Table 2. Pain Level and Sleep Quality.

\begin{tabular}{lllll}
\hline \multirow{2}{*}{ Projects } & \multicolumn{2}{l}{ Pain Level } & \multicolumn{2}{l}{ Sleep Quality } \\
\cline { 2 - 5 } & BN & FN & BN & FN \\
\hline Control Group & $8.02 \pm 2.28$ & $3.04 \pm 0.44$ & $7.24 \pm 2.65$ & $10.49 \pm 2.51$ \\
Intervention Group & $7.56 \pm 2.13$ & $1.21 \pm 0.33$ & $7.48 \pm 2.73$ & $13.74 \pm 2.34$ \\
$t$ & 0.313 & 33.091 & 0.312 & 43.51 \\
$P$ & 0.044 & $<0.005$ & 0.031 & $<0.005$ \\
\hline
\end{tabular}

$\mathrm{BN}=$ Before the Nursing.

$\mathrm{FN}=$ After the Nursing.

The satisfaction of Patients was collected by NSNS, we collected them after treatment (Table 3). In result of satisfaction, participants preferred the new nursing measures of intervention group, the assessments of very well were made on $88(71.4 \%)$ people in intervention group.
Table 3. Satisfaction of Patients.

\begin{tabular}{llll}
\hline \multirow{2}{*}{ Projects } & \multicolumn{2}{l}{ Satisfaction } & \\
\cline { 2 - 4 } & Very Well & Good & Dissatisfaction \\
\hline Control Group & $56(50.0 \%)$ & $37(33.0 \%)$ & $19(17.0 \%)$ \\
Intervention Group & $88(71.4 \%)$ & $17(15.2 \%)$ & $7(13.4 \%)$ \\
\hline
\end{tabular}

\section{Discussion}

Looking into Watson's theory, humanistic caring is a fundamental belief in the internal power of the care process to produce growth and change for people [18]. In the 21st century, health professionals are expected to provide more than medical care, going more in the direction of holistic care. Medicine can be not only a science but can also be more humanistic by assisting people to seek their own value of life and achieve self-actualization and self-healing.

Following to outcome of collection, the nursing measure of humanistic care had better improvement than traditional nursing measure. The patients require more new nursing measure about mental. In pain level and sleep quality, the intervention group had lower pain level than control group, the humanistic care can relieve pain in the treatment process. Additionally, the patients of intervention group had better 
sleep in the treatment process. But the influence of the new nursing measure was non-ideal in the outcome, its improvement had not strong to changed the pain level and the sleep quality as the new nursing measure require more cost in process. As the result of satisfaction of patients, the participants was more satisfied with new nursing measure of humanistic care. Although the satisfaction data was sample for the result, it had significant trend in satisfaction improvement.

\section{Conclusion}

In conclusion, humanistic care can be effectively improved the outcome of treatment on gynecological tumor patients. The nursing measure of humanistic care made not only pain level of patient in treatment process was reduce but also sleep quality of patient was improved. However, the improvement effect was not strong for the outcome of nursing so that the new nursing measure had low effective rate in the treatment process. In addition, patients had higher satisfaction for new the nursing measure associated with humanistic care.

\section{References}

[1] Frisch N., Dossey B., Guzzeta C., Quinn J. AHNA Standards of Holistic Nursing Practice: Guidelines for Caring and Healing. Aspen, Gaithersburg, MD. 2000.

[2] Buckley, J. Holism and a health-promoting approach to palliative care. Int. J. Palliat. Care. 2002; 8: 505-508.

[3] Sarkis, J., Skoner, M., 1987. Analysis of the concept of holism in nursing practice. Holist. Nurs. Pract. 1987; 2: 61-70.

[4] Leininger, M. M. Leininger's theory of nursing: cultural care diversity and universality. Nurs. Sci. Q. 1988; 1 (4): 152-160.

[5] Woods, M. An ethic of care in nursing: past, present and future considerations. Ethics Social Welfare. 2011; 5 (3): 266-276.

[6] Raja S., Hasnain M., Vadakumchery T., Hamad J., Shah R., Hoersch M. Identifying elements of patient-centered care in underserved populations: a qualitative study of patient perspectives. Plos One. 2015; 10 (5): 0126708.
[7] Xu J., Liu Y. L., Luo J. Investigation on status quo of caring capacity of nursing staff and influencing factors. Chin Nurs Res. 2009; 23: 3306-3308.

[8] Chen H., Zheng M. A., Lei W. N. Research on caring ability of surgical nurses in a 2A-level hospital. J Nurs Admin. 2012; 12 (4): 255-256.

[9] Watson, J. Watsons theory of human caring and subjective living experiences: carative factors/caritas processes as a disciplinary guide to the professional nursing practice. Texto \& Contexto Enf. 2017; 16 (1): 129-135.

[10] Fernandezabascal E. G., Martindiaz M. D. Relations between dimensions of emotional intelligence, specific aspects of empathy, and non-verbal sensitivity. Front. Psychol. 2019; 10.

[11] Hidayati L., Rifai F., Nimah L. Emotional Intelligence and Caring Behavior Among Muslim Nurse: A Study in Religious-Based Hospital in Surabaya Indonesia. 2017; 41.

[12] Hajbaghery M. A., Shahsavarloo Z. R. Assessing the nursing and midwifery students competencies in communication with patients with severe communication problems. Nurs. Midwifery Stud. 2014; 3 (2): e18143.

[13] Pun BT, et al. Caring for critically ill patients with the ABCDEF bundle: results of the ICU liberation collaborative in over 15,000 adults. Crit Care Med 2019; 47 (1): 3-14.

[14] MacLeod M., Thomson H. A., Upton C., Scott R., Chesson R. A.. Seamless Care in Physiotherapy: Does it exist at the interface of primary and secondary care? Physiotherapy. 2002; 11 (88): 677-686.

[15] Bijur, P. E., Silver, W., Gallagher, E. J. Reliability of the visual analog scale for measurement of acute pain. Acad. Emerg. Med. 2001; 8: 1153-1157.

[16] Buysse DJ, Reynolds CF, Monk TH, et al. The Pittsburgh Sleep Quality Index: a new instrument for psychiatric practice and research. Psychiatry Res 1989; 28: 193-213.

[17] Thomas LH, Bond S. Measuring patients' satisfaction with nursing [J]. Journal of Advanced Nursing. 1993; 23: 747-756.

[18] Watson J. Love and caring ethics of face and hand- an invitation to the heart and our deep humanity. Nurs Adm Q 2003; 27: 197-202. 